\title{
The perfluoroalkyl carboxylic acids (PFCAs) and perfluoroalkane sulfonates (PFSAs) contamination level in spices
}

\author{
Magdalena Surma $^{1} \cdot$ Mariusz Piskuła $^{2} \cdot$ Wiesław Wiczkowski $^{2} \cdot$ Henryk Zieliński $^{2}$
}

Received: 21 March 2016 / Accepted: 27 June 2016 / Published online: 15 July 2016

(C) The Author(s) 2016. This article is published with open access at Springerlink.com

\begin{abstract}
Spices have been used since ancient times. Although they have been employed mainly as flavoring and coloring agents, their role in food safety is of increasing concern. In this study, the usefulness of a modified QuEChERS method, based on the d-SPE, with micro-HPLC-MS/ MS system for the determination of selected perfluoroalkyl carboxylic acids (PFCAs) and perfluoroalkane sulfonates (PFSAs) in spices was addressed. The commonly used spices in Spain and Slovakia were investigated. The studies showed the presence of perfluorooctanoic acid in 19 spices of Spanish and Slovak origin, and it ranged from $0.11 \mathrm{ng} \mathrm{g}^{-1}$ for garlic to $0.67 \mathrm{ng} \mathrm{g}^{-1}$ for peppermint. The perfluorobutanoic acid was quantified in 10 Slovak spices (from $1.13 \mathrm{ng} \mathrm{g}^{-1}$ for allspice to $37.82 \mathrm{ng} \mathrm{g}^{-} 1$ for star anise), whereas perfluorobutane sulfonate was identified only in 12 Spanish spices and it ranged from $0.24 \mathrm{ng} \mathrm{g}^{-1}$ for cinnamon to $1.01 \mathrm{ng} \mathrm{g}^{-1}$ for coriander. In contrast, perfluoroheptanoic acid was identified only in Slovak cardamom (1.94 $\left.\mathrm{ng} \mathrm{g}^{-1}\right)$ and coriander $\left(0.74 \mathrm{ng} \mathrm{g}^{-1}\right)$. The average consumption of spices in Europe is approximately $0.5 \mathrm{~g} \mathrm{day}^{-1}$, while in Asia and northern Africa, it is many times higher. Average content of PFASs in this evaluation has a value $4.67 \mathrm{ng} \mathrm{g}^{-1}$ giving $2.33 \mathrm{ng} \mathrm{day}^{-1}$ per person. This study showed that daily used spices may contribute
\end{abstract}

Magdalena Surma

m.surma@ur.krakow.pl

1 Malopolska Centre of Food Monitoring, Faculty of Food Technology, University of Agriculture in Krakow, ul. Balicka 122, 30-149 Krakow, Poland

2 Division of Food Science, Department of Chemistry and Biodynamics of Food, Institute of Animal Reproduction and Food Research of the Polish Academy of Sciences, Tuwima St.10, 10-748 Olsztyn, Poland to the overall contamination of food by perfluoroalkyl substances.

Keywords Perfluoroalkyl carboxylic acids (PFCAs) . Perfluoroalkane sulfonates (PFSAs) · QuEChERS method · d-SPE · Micro-HPLC-MS/MS · Spices

\section{Introduction}

Spices are mostly plant origin substances added to food in order to improve their flavor, aroma and functionality. They are used also as food preservatives and folk medicines. Many spices also have been recognized as having inflammatory [1], antimicrobial [2], antifungal [3], antimutagenic and anticarcinogenic properties [4]. A growing body of epidemiological and preclinical evidence points to culinary herbs and spices as minor dietary constituents with multiple anticancer characteristics $[4,5]$. They can be classified according to several criteria, such as: due to the origin, active substance content, whether due to parts of plants, from which it is derived. They can be prepared from fruits (pimento), fully ripe berries (white pepper), flower buds (clove), roots (ginger) or bark (cinnamon) [6] and can be added to food in form of whole or ground material or as extracts. Although spices contribute little to weight on our dish, they can be important contributors to our daily antioxidants [7] intake, especially in dietary cultures where spices are used regularly [8]. Due to the origin, cultivation conditions and type of processing, spices may also be a source of some contaminants such as pesticides $[9,10]$, heavy metals [11], illegal dyes [12, 13], mycotoxins [14, 15] and perfluoroalkyl substances.

Perfluoroalkyl substances (PFASs) are a wide group of synthetic compounds with high resistance to chemical, 
thermal, or biological degradation. PFASs comprise a diverse class of chemicals consisting of an alkyl chain which is partially of fully fluorinated and have different functional groups attached. Among them are perfluoroalkyl carboxylic acids (PFCAs) and perfluoroalkane sulfonates (PFSAs), which are the subject of our interest. They are widely used in various industrial and consumer applications, mainly thanks to their unique ability to repel both water and oil. As a consequence, these compounds show a global distribution all over the world and have been detected not only in environment samples $[16,17]$ but also in human blood $[18,19]$. It show persistence in the environment [20] and some of them are related to different carcinogenic actions [21]. For example, perfluorooctanoic acid (PFOA) has been identified as a potent hepatocarcinogen in rodents [21, 22].

Nevertheless, as spices are consumed all the time in daily meal even though in tiny amount, long-term exposure to persistent organic pollutants may pose a health risk. However, no information is available on the presence of PFASs in spices up till now. Therefore, it is of importance to monitor them for the most often occurring PFASs identification and illustrate the food contamination level. What is more important, there is currently no legislation for perfluoroalkyl substances in food or feed within the EU. The EFSA Scientific Panel on Food Additives, Flavourings, Processing Aids and Materials in Contact with Food (AFC) issued an opinion on the safety of ammonium salt of PFOA as a food contact material, but this has not so far led to regulatory measures. Currently, there is a proposal for hazard classification for PFOS (perfluorooctane sulfonate) in the European Inventory of Existing Commercial Chemical Substances (EINECS). The Conference of the Parties of the Stockholm Convention on Persistent Organic Pollutants (POPs) at its fourth meeting held in May 2009, listed nine additional chemicals as new POPs. PFOS and their salts, as well as perfluorooctane sulfonyl fluoride are among these new POPs [23]. Moreover, in 2006, EPA (Environmental Protection Agency) invited the eight major fluoropolymer and telomere manufacturers to join in a global stewardship program with which was at first aimed to commit to achieve, no later than 2010, a $95 \%$ reduction, measured from a year 2000 baseline, in both facility emissions to all media of PFOA, precursor chemicals that can break down to PFOA, and related higher homologue chemicals, and product content levels of these chemicals and secondly to commit to working toward the elimination of these chemicals from emissions and products by 2015. In January 2015, EPA released the most recent reports, for years 2013 and 2014, from participating companies on progress they have made in reaching the program's phase-out goals. Results show that the companies are on track to reach the program's goal of phasing out these chemicals by the end of 2015 [24].
Spices as foods must comply with the requirements of food law. There are Regulation (EC) No 178/2002 of The European Parliament and of the Council of 28 January 2002 laying down the general principles and requirements of food law, establishing the European Food Safety Authority and laying down procedures in matters of food safety and the Act of 25 August 2006 on food and nutrition safety. There is no legislation for perfluoroalkyl substances in food or feed within the EU [25]. The preliminary findings of EFSA indicate the need to identify PFASs in raw material as well as in food of plant origin [26]. Now there is increasing number of evidences that the pollution by PFASs, is a global issue, given the transboundary movement of these compounds [27]. EFSA's Scientific Panel on Contaminants in the Food Chain therefore recommended that further data on perfluoroalkylated substance levels in food and humans would be desirable [25]. In March 2010, Commission Recommendation 2010/161/EU invited the Member States to monitor the presence of PFOS and PFOA in food systems, compounds similar to them but with different chain length and their precursors [28]. For this purpose, according to above-mentioned document, it is required to use a method of analysis that has been proven to generate reliable results. Ideally, the recovery rates should be in the range $70-120 \%$, with limits of quantification (LOQ) of $1 \mu \mathrm{g} \mathrm{kg}^{-1}$. Therefore, a sensitive method of perfluoroalkyl carboxylic acids and perfluoroalkane sulfonates determination in spices samples is extremely needed. Currently, due to its high sensitivity and selectivity, liquid chromatography hyphenated with tandem mass spectrometry (LC-MS/MS) operated in the multiple reaction monitoring mode (MRM) is the preferred technique for a quantitation of PFCAs and PFSAs trace levels. Moreover, micro-HPLC technique provides higher peak capacity, greater resolution, increased sensitivity and a higher speed of analysis compared to conventional LC system [29], mainly in combination with MS/MS.

The sample preparation method for PFASs determination is a challenge not only because of their low concentration levels in food samples but also of the complexity of matrices. Therefore, efficient sample preparation procedures and very sensitive determination technique are required. One of the three most common approaches such as pressurized liquid extraction [21], alkaline digestion [30-32] and ion pair extraction [20] was employed for sample preparation for PFASs analysis; however, each method showed some limitations. Procedures based on ion pair extraction have been widely used for this purpose, although sometimes these suffer from matrix effects. Tetra-n-butylammonium hydrogen sulfate solution and sodium carbonate buffer at $\mathrm{pH} 10$ are used as the ionpairing agents and methyl tert-butyl ether (MTBE) as the 
extractant $[33,34]$. This method is relatively laborious and suffers from drawbacks such as co-extraction lipids and other lipophilic matrix components, which significantly complicate further chromatographic analysis. Several studies have been performed using $\mathrm{KOH}$ digestion or filtration followed by solid phase extraction (SPE) $[35,36]$. SPE is a less laborious and faster alternative. Because of the different polarities of PFASs, different SPE cartridges have been evaluated. The widely used Oasis WAX cartridges yield good recoveries for short-chain (C4-C6) PFASs, whereas less polar phases $\left(\mathrm{C}_{18}\right.$ and Oasis HLB) may be used for longer-chain PFASs. Unfortunately, none of the cartridges available at the market allows simultaneous retaining of all commonly monitored representatives of perfluorinated compounds [37]. Therefore, there is a need to develop an innovative approach that would allow for the accurate determination of an entire set of analytes of concern at an ultra-trace level and also high-throughput sample handling. Nowadays, there is a strong tendency to develop simply, minimum steps, and effective for cleaning up complex samples and useful in the analysis of residues in foods methods. Such features a fast and inexpensive extraction QuEChERS (Quick, Easy, Cheap, Effective, Rugged, Safe), method has been shown. It was introduced for a first time by Anastassiades [38]. Extraction based on partitioning via salting out extraction involving the equilibrium between an aqueous and an organic layer is the first step. Dispersive solid phase extraction (d-SPE) that involves further cleanup using combinations of anhydrous salt and various sorbents to remove interfering substances is the second step. The available evidence indicates for the benefits of use polymer-based ENV SPE Bulk Sorbent for the determination of perfluoroalkyl carboxylic acids (PFCAs) and perfluoroalkane sulfonates (PFSAs). This sample treatment has been previously reported for sample preparation for perfluoroalkyl substances determination in different food matrix [39] and animal tissues [40]. Previously, this method was also used for analysis of pesticides residues in vegetables [41], but it has been extended to other residues and matrixes [42-44].

To our best knowledge, the existing literature provides lack of information about the PFASs determination in spices, and thus no one used the QuEChERS methodology for this reason. Consequently, the aim of this study was to apply the modified QuEChERS method, based on the dispersive solid phase extraction (d-SPE), with micro-HPLC-MS/MS system [40] for the determination of selected perfluoroalkyl carboxylic acids (PFCAs) and perfluoroalkane sulfonates (PFSAs) in spices. This study tries to evaluate for the first time an extent of spices contamination by perfluoroalkyl substances which may be important for further EFSA recommendation on the health risk of these compounds in humans.

\section{Experimental}

\section{Chemicals and reagents}

Magnesium sulfate anhydrous p.a. and sodium chloride p.a. were purchased from POCh SA, Poland. ENV (styrene-divinylbenzene) SPE Bulk Sorbent derived from Agilent Technologies, USA. Reagents in MS grade including acetonitrile $(\mathrm{MeCN})$, methanol $(\mathrm{MeOH})$, formic acid (FA) were purchased from Sigma Chemical Co., St. Louis, MO. Water was purified with a Mili-Q system, Millipore, Bedford, USA. Acetonitrile (for extraction) HPLC grade was purchased from Merck KGaA, Germany. Native PFASs Solution/Mixture contains sulfonates: perfluorobutane (PFBS), perfluorohexane (PFHS), perfluorooctane (PFOS), and acids: perfluorobutanoic (PFBA), perfluoropentanoic (PFPeA), perfluorohexanoic (PFHxA), perfluoroheptanoic (PFHpA), perfluorooctanoic (PFOA), perfluorononanoic (PFNA), perfluorodecanoic (PFDA) and $1,2,3,4-{ }^{13} \mathrm{C}$ - labeled PFOA were obtained from Wellington Laboratories, Canada. Stock, intermediate and working standard solutions of native PFASs and $1,2,3,4-{ }^{13} \mathrm{C}_{4}$ labeled PFOA (IS-internal standard) was prepared in acetonitrile. Stock solution of PFASs at the concentration of $5 \mu \mathrm{g} \mathrm{mL}-1$ and $1,2,3,4-{ }^{13} \mathrm{C}_{4}$-labeled PFOA at a concentration of $49 \mu \mathrm{g} \mathrm{mL} \mathrm{m}^{-1}$ were purchased as a solution prepared in methanol. Intermediate $\left(100 \mathrm{ng} \mathrm{mL}^{-1}\right)$ and working $\left(1 \mathrm{ng} \mathrm{mL}^{-1}\right)$ standard solutions of native PFASs and IS were prepared in $20 \% \mathrm{MeOH}(\mathrm{v} / \mathrm{v})$ with $1 \%(\mathrm{v} / \mathrm{v})$ of formic acid.

Matrix-matched calibration standards at concentrations of between 1 and $20 \mathrm{ng} \mathrm{mL}^{-1}$ were prepared by diluting the standard mixture solution to the corresponding blank sample extracts. The intention was to compare the matrix effects in calibration. A series of standard solutions in pure solvent were prepared by dilution of the standard mixture solution in $20 \% \mathrm{MeOH}(\mathrm{v} / \mathrm{v})$ with $1 \%(\mathrm{v} / \mathrm{v})$ of formic acid at the same range as before and then were used for calibration curves construction. In both cases, $20 \mu \mathrm{L}$ of the $1,2,3,4-{ }^{13} \mathrm{C}_{4}$-labeled PFOA solution (concentration) was added to each standard solution. A series of standard solutions were prepared in triplicate.

\section{Material}

The analyzed spice samples, as a powder, in the amount about $100 \mathrm{~g}$ each, originated from two EU countries (Slovakia and Spain). Twelve types of spices collected for the study were as follows: anise (Pimpinella anisum), star anise (Illicum verum), white pepper (Piper nigrum), fennel (Foeniculum vulgare), cardamom (Elettaria cardamomum), clove (Syzygium aromaticum), coriander (Coriandrum 
sativum), nutmeg (Myristica fragrans), allspice (Pimenta dioica), cinnamon (Cinnamomum burmanni), vanilla (Vanilla planifolia), ginger (Zingiber officinale). Additionally, peppermint (Mentha piperita), parsley (Petroselinum crispum), thyme (Thymus vulgaris), laurel (Laurus nobilis), two oreganos (Origanum vulgare), garlic (Allium sativum), cumin (Cuminum cyminum), black paper (Piper nigrum), and two varieties of hot pepper (Capsicum annиum) (mild and hot) from Spain were analyzed.

\section{Equipment}

The micro-HPLC system (LC200, Eksigent, Canada) consisted of a multi-channel pump, an autosampler (set at $4{ }^{\circ} \mathrm{C}$ ), a column oven and a system controller coupled with a mass spectrometer (QTRAP 5500, AB SCIEX, Canada) consisting of a triple quadrupole, ion trap and ion source of electro-spray ionization (ESI) and controlled by the Analyst 1.5.1 software was used to perform the LC-MS/MS analyses. All chromatographic determinations were performed on $\mathrm{HALO} \mathrm{C}_{18}(50 \mathrm{~mm} \times 0.5 \mathrm{~mm} \times 2.7 \mu \mathrm{m})$ column (Eksigent, Canada) at $45^{\circ} \mathrm{C}$ with the flow rate of $20 \mu \mathrm{L} \mathrm{min}{ }^{-1}$. Compounds were eluted in gradient system composed of water/formic acid (99.0/1.0, phase A) and acetonitrile/ formic acid (99.0/1.0, phase B). Gradient was as follows: $40 \%$ B (0-0.5 min $), 40-90 \%$ B $(0.5-3.0 \mathrm{~min}), 90 \% \mathrm{~B}$ (3.0-4.0 $\mathrm{min}), 90-40 \%(4.0-4.2 \mathrm{~min})$ and $40 \%(4.2-$ $5.0 \mathrm{~min})$. Qualitative and quantitative analysis was made using Multiple Reaction Monitoring (MRM) method. Optimal identification of compounds analyzed was achieved under the following conditions: negative ionization, curtain gas: $25 \mathrm{~L} \mathrm{~min}{ }^{-1}$, collision gas: $9 \mathrm{~L} \mathrm{~min}^{-1}$, ion spray voltage: $-4500 \mathrm{~V}$, temperature: $350{ }^{\circ} \mathrm{C}, 1$ ion source gas: $30 \mathrm{~L} /$ min, 2 ion source gas: $35 \mathrm{~L} / \mathrm{min}$, declustering potential: -30 : $-85 \mathrm{~V}$, entrance potential: $-10 \mathrm{~V}$, collision energy: -10 to $-65 \mathrm{eV}$, collision cell exit potential: $-10:-38 \mathrm{~V}$ (Surma, Wiczkowski, Cieślik \& Zieliński, 2015).

MPW 351R Centrifuge (MPW Med. Instruments, Warsaw, Poland) was used for sample preparation. The vacuum Concentrator plus (Eppendorf AG, Hamburg, Germany) was used for the extracts concentration.

\section{Sample preparation method for PFCAs and PFSAs determination}

The spices sample preparation for perfluoroalkyl carboxylic acids and perfluoroalkane sulfonates determination, based on dispersive solid phase extraction (d-SPE) followed by micro-HPLC-MS/MS, was conducted according to the methodology evaluated and validated in the previous study [39]. However, considering the fact that the majority of investigated spices has a very intense color, application of additional sorbent for sample clean-up was considered.
Based on previous experiments with containing pigments samples preparation, GCB (graphitized carbon black) was selected from available silica-based sorbents (silica gel, florisil, $\mathrm{SAX}$ and $\mathrm{NH}_{2}$ ). Two variants of method were tested with or without GCB and they were marked as follow: 1 (ENV) and 2 (ENV + GCB). The extraction process was conducted as follow: 2 grams of a representative portion of spice were weighted into a $50-\mathrm{mL}$ centrifuge tube and spiked with $20 \mu \mathrm{l}$ of IS (internal standard) solution $\left(2.5 \mu \mathrm{g} \mathrm{mL}^{-1}\right)$. Then, $5 \mathrm{~mL}$ of water and $10 \mathrm{~mL}$ of $\mathrm{MeCN}$ with $150 \mu \mathrm{L}$ of FA were added to each tube and the mixture was sonicated and vigorously shaken for $1 \mathrm{~min}$, respectively. After that $1 \mathrm{~g} \mathrm{NaCl}$ and $4 \mathrm{~g} \mathrm{MgSO}_{4}$ were added, the tube was shaken immediately after addition of the salt. Then each sample was shaken vigorously for $1 \mathrm{~min}$ and centrifuged for $15 \mathrm{~min}$ at $8700 \mathrm{RCF}$. Next, $6 \mathrm{~mL}$ of the supernatant was transferred into a PP $15-\mathrm{mL}$ tube containing 0,15 g ENV SPE Bulk Sorbent (method 1) and additionally, apart from ENV, GCB (method 2), to d-SPE used for extracts clean-up, and $0.900 \mathrm{~g} \mathrm{MgSO}_{4}$. After $30 \mathrm{~s}$ shaking and $5 \mathrm{~min}$ centrifugation at $5000 \mathrm{RCF}, 4 \mathrm{~mL}$ amount from each extracts was transferred into a 4-ml tubes and evaporated to dryness in the concentrator at $40{ }^{\circ} \mathrm{C}$. The residues were dissolved in $1 \mathrm{~mL}$ of methanol. Just before injection, the samples were diluted fivefold in acidified $\mathrm{dH}_{2} \mathrm{O}$ (distillate water with $1 \%(\mathrm{v} / \mathrm{v})$ of formic acid addition). Finally, all cleaned up samples were analyzed by micro-HPL-MS/MS. Blank samples and reagent blanks were prepared according the same procedure. Each sample was prepared in triplicate. The most appropriate variant of the QuEChERS method was applied for perfluoroalkyl substances determination in spice samples. To better illustrate, the final sample preparation method is shown in Fig. 1.

As of now, spices and related food matrices with certified concentrations of perfluoroalkyl substances are not commonly available. Thus, the usefulness of the method was verified on the basis of the recovery ratio of analyzed compounds (analysis of fortified samples) which were previously used for recovery studies. Recovery studies involved homogenized samples of cinnamon being spiked with the standard solution of ten PFASs (7 perfluoroalkyl carboxylic acids and 3 perfluoroalkane sulfonates) to the fortification level of $0.005 \mathrm{mg} \mathrm{kg}^{-1}$. The procedure of sample preparation was the same as described above, except that the sample was fortified by native standard solution of PFASs at the beginning, mixed and left to stand for $15 \mathrm{~min}$ at room temperature prior to extraction.

The PFCAs and PFSAs involved in this study were identified by the retention time and MRM ion pairs. Calibration curves were constructed by plotting the ratio of the peak areas, divided by the peak area of the $1,2,3,4{ }^{13} \mathrm{C}_{4^{-}}$ labeled PFOA, against concentration of the analyte. Peak areas of the analytes from blank matrix (when was present) 
Fig. 1 Schema of the final sample preparation method

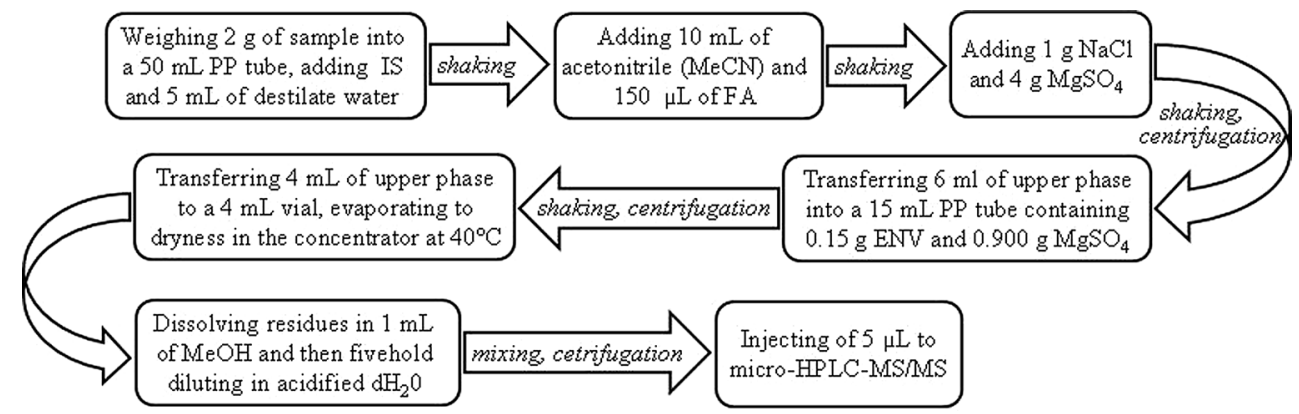

Table 1 Retention times and MRM ion pairs of analyzed perfluoroalkyl substances (PFASs)

\begin{tabular}{llll}
\hline PFCs name & Acronym & $R_{\mathrm{t}}[\mathrm{min}]$ & MRM ion pairs \\
\hline Perfluorobutanoic acid & PFBA & 0.58 & $213 / 169$ \\
Perfluoropentanoic acid & PFPeA & 0.87 & $263 / 219$ \\
Perfluorobutane sulfonate & PFBS & 1.34 & $299 / 80$ \\
Perfluorohexanoic acid & PFHxA & 1.36 & $313 / 269$ \\
Perfluoroheptanoic acid & PFHpA & 1.79 & $363 / 319$ \\
${ }^{13}$ C- Perfluorooctanoic acid & L-PFOA & 2.19 & $417 / 372$ \\
Perfluorooctanoic acid & PFOA & 2.20 & $413 / 369$ \\
Perfluorohexane sulfonate & PFHS & 2.27 & $399 / 80$ \\
Perfluorononanoic acid & PFNA & 2.59 & $463 / 419$ \\
Perfluorodecanoic acid & PFDA & 3.02 & $513 / 469$ \\
Perfluorooctane sulfonate & PFOS & 3.12 & $499 / 80$ \\
\hline
\end{tabular}

PFASs perfluoroalkyl substances, $R_{\mathrm{t}}$ retention time, MRM multiple reaction monitoring

have been removed from analytes peaks area from fortified samples. Retention times and MRM ion pairs for analyzed PFASs are summarized in Table 1.

The analytical performance of the using QuEChERS method based on dispersive solid phase extraction for studied perfluoroalkyl substances was examined by looking at its linearity, selectivity, recovery, repeatability, the limit of detection (LOD), and limit of quantification (LOQ).

\section{Results and discussion}

\section{Comparison of QuEChERS method with and without additional sorbent-recovery study}

The recovery values for all tested analytes for fortified samples of cinnamon are presented in Fig. 2. They ranged from 87 to $105 \%$ for method 1 (based on ENV sorbent) and from 67 to $94 \%$ for method 2 (which in addition to ENV sorbent uses GCB). The better recovery ratios (according to the Commission Recommendation 2010/161/EU of 70-120 \%) with RSD lower than $10 \%$ for all analyzed perfluoroalkyl substances were obtained for the method 1 used ENV sorbent for extract clean-up. Method 2 uses the addition of GCB apart from ENV resulted in more diversified values, not be in the range of values set by Commission Recommendation 2010/161/EU (70-120\%). The use of additional sorbent-GCB in the sample preparation step caused decrease of the recovery values for all tested analytes. Moreover, the RSD (related standard deviation) value higher than $10 \%$ was noted for one PFAS-perfluorononanoic acid (PFNA)
Fig. 2 Recovery ratios [\%] of two tested methods for all investigated analytes

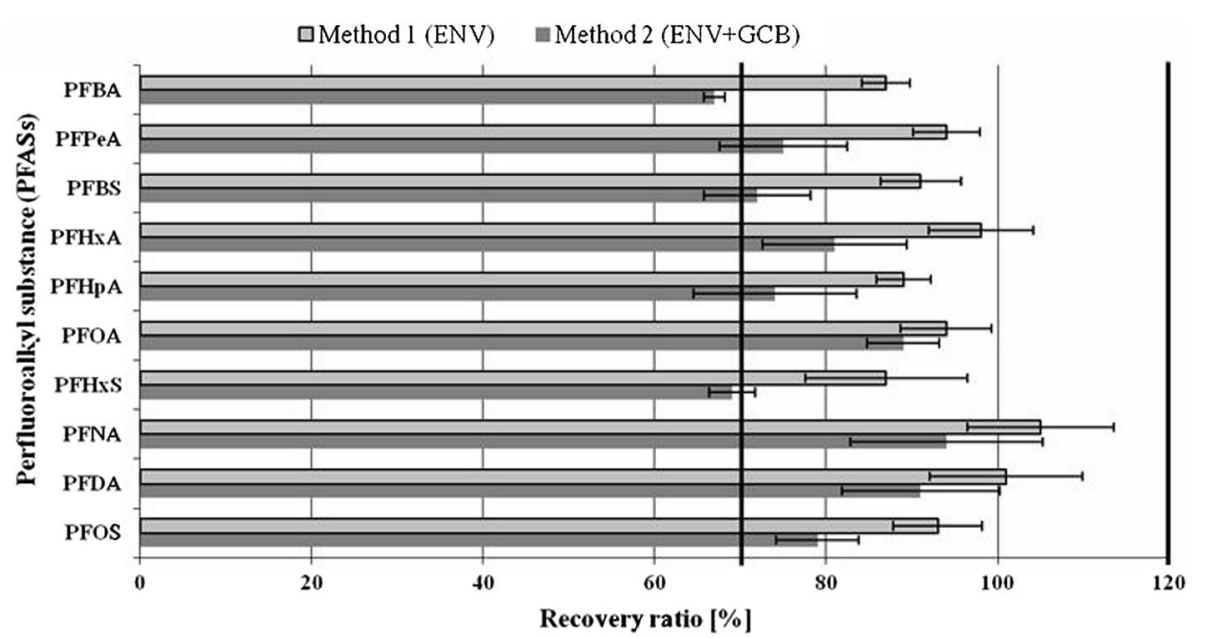


Table 2 Data of the quantification of determined PFASs

\begin{tabular}{llllll}
\hline PFCs name & Acronym & $a$ & $R^{2}$ & LOD $\left[\mathrm{ng} \mathrm{g}^{-1}\right]$ & LOQ $\left[\mathrm{ng} \mathrm{g}^{-1}\right]$ \\
\hline Perfluorobutanoic acid & PFBA & 0.2036 & 0.999 & 0.073 & 0.219 \\
Perfluoropentanoic acid & PFPeA & 0.1943 & 0.999 & 0.041 & 0.123 \\
Perfluorobutane sulfonate & PFBS & 0.2205 & 0.999 & 0.038 & 0.114 \\
Perfluorohexanoic acid & PFHxA & 0.1932 & 0.999 & 0.051 & 0.153 \\
Perfluoroheptanoic acid & PFHpA & 0.2168 & 0.999 & 0.023 & 0.069 \\
Perfluorooctanoic acid & PFOA & 0.4509 & 0.999 & 0.047 & 0.141 \\
Perfluorohexane sulfonate & PFHS & 0.4235 & 0.999 & 0.013 & 0.039 \\
Perfluorononanoic acid & PFNA & 0.1140 & 0.999 & 0.031 & 0.093 \\
Perfluorodecanoic acid & PFDA & 0.1430 & 0.999 & 0.029 & 0.087 \\
Perfluorooctane sulfonate & PFOS & 0.1837 & 0.999 & 0.015 & 0.045 \\
\hline
\end{tabular}

$a$ calibration slope, $R^{2}$ coefficients of determination, $L O D$ limit of detection, $L O Q$ limit of quantification PFPeA, PFHxA, PFNA, PFDA, PFHS and PFOS were not detected in any spice samples with value $11,2 \%$. At present, there is a lack of information about the allowed RSD value for recovery ratios for perfluoroalkyl substances determination in Commission Recommendation 2010/161/EU. However, a good laboratory practice and validation guidelines indicate the value of $10 \%$.

\section{Analytical performance of the method}

A method of least squares was used to obtain equations of calibration curves $(y=a x+b)$. A goodness of fit being given by coefficient of determination $\left(R^{2}\right)$, which is an evidence that linearity was observed for analyzed PFASs in the range of concentrations from 1 to $20 \mathrm{ng} \mathrm{mL}^{-1}$ (Table 2). Correlation coefficients were statistically significant and slope at a significance level $(\alpha)$ equal to 0.05 . For the same hypothesis, the intercept from the regression models was not significantly different to zero. This means that absence of compound in any analyzed sample would imply that the analytical signal should be zero.

Recovery studies were conducted after cinnamon sample fortification of selected PFASs to the level of $0.005 \mathrm{mg} \mathrm{kg}^{-1}$ (Fig. 2). The received recovery values from $87 \pm 2.8 \%$ for PFBA to $105 \pm 8.5 \%$ for PFNA being in good agreement with the Commission Recommendation 2010/161/EU on the monitoring of perfluoroalkylated substances in food [28].

The repeatability, expressed as the relative standard deviation (RSD) of the analyzed samples, was lower than $10 \%$ for all target analytes. There is a lack of information about the allowed RSD value for recovery ratios for PFASs determination in Commission Recommendation 2010/161/EU. However, good laboratory practice and validation guidelines indicate the value of $10 \%$. The limit of detection (LOD) was calculated as three times higher than the level of noise, and the limit of quantification (LOQ) was equal to ten times of the noise level. The level of noise was measured from the chromatograms obtained for the standard solutions with the lowest concentration, i.e. $1 \mathrm{ng} \mathrm{mL}{ }^{-1}$. The LOD and LOQ for the used method calculated as a ratio signal to noise showed values from 0.013 to $0.039 \mu \mathrm{g} \mathrm{kg}^{-1}$ for PFHS to $0.073-0.219 \mu \mathrm{g} \mathrm{kg}^{-1}$ for PFBA, respectively (Table 2). LOQ values were in good agreement with value specified in the Commission Recommendation 2010/161/EU (1 $\mathrm{\mu g} \mathrm{kg}^{-1}$ ) [28]. The sensitivity calculated as calibration slope coefficient was the highest for perfluorooctanoic acid while the lowest for perfluorononanoic acid.

Matrix effects (ME) (suppression or enhancement) were evaluated through the matrix effect percentage (\% $\mathrm{ME})$ calculation. The percentage was calculated as a difference between the slopes of the matrix match calibration curve and the solvent one according to literature report [45]. Signal enhancement would occur if the percentage of the difference between these slopes were positive. If it was negative, it would be indicative of signal suppression. Depending on the \% ME value would be classified into three categories. A percentage between -20 and $20 \%$ was considered as no matrix effect, because this variation would be close to the repeatability values. A medium matrix effect occurred when the values were between -50 and $-20 \%$ or 20 and $50 \%$, and a strong matrix effect would be below $-50 \%$ or above $+50 \%$. In the studied matrix (cinnamon), no matrix effects were observed. For each analyzed PFASs \%, ME ranged from -7.2 to $8.5 \%$. Therefore, in later determination, solvent calibration curves were used to PFCAs and PFSAs content calculation in analyzed spice samples.

\section{Analysis of spice samples}

In present study, we decided to fill out existing gap in the spices contamination with perfluoroalkyl substances. The results of spice samples analysis are presented in 
Table 3 Content of selected PFASs in analyzed spice samples [ng g ${ }^{-1}$ ]

\begin{tabular}{|c|c|c|c|c|c|c|c|c|c|}
\hline \multicolumn{2}{|l|}{ Spice sample } & \multicolumn{8}{|c|}{ Concentration $\left[\mathrm{ng} \mathrm{g}^{-1}\right]$} \\
\hline \multirow[t]{2}{*}{ Type } & \multirow[t]{2}{*}{ Binomial name } & \multirow{2}{*}{\multicolumn{2}{|c|}{$\begin{array}{l}\text { Country of } \\
\text { origin }\end{array}$}} & \multicolumn{3}{|l|}{ PFCAs } & \multirow[t]{2}{*}{$\sum$ PFCAs } & \multirow{2}{*}{$\begin{array}{l}\text { PFASs } \\
\text { PFBS }\end{array}$} & \multirow[t]{2}{*}{$\sum$ PFASs } \\
\hline & & & & PFBA & PFHpA & PFOA & & & \\
\hline \multirow[t]{2}{*}{ Anise } & \multirow[t]{2}{*}{ Pimpinella anisum } & Slovaki & & $26.19 \pm 0.78$ & nd & $0.22 \pm 0.00$ & 26.41 & nd & - \\
\hline & & Spain & & nd & nd & $0.52 \pm 0.03$ & 0.52 & $0.82 \pm 0.08$ & 0.82 \\
\hline \multirow[t]{2}{*}{ Star anise } & \multirow[t]{2}{*}{ Illicum verum } & Slovaki & & $37.82 \pm 1.43$ & nd & nd & 37.82 & nd & - \\
\hline & & Spain & & nd & nd & $0.22 \pm 0.01$ & 0.22 & $0.64 \pm 0.03$ & 0.64 \\
\hline \multirow[t]{2}{*}{ White pepper } & \multirow[t]{2}{*}{ Piper nigrum } & Slovaki & & $1.88 \pm 0.09$ & nd & nd & 1.88 & nd & - \\
\hline & & Spain & & nd & nd & nd & - & nd & - \\
\hline \multirow[t]{2}{*}{ Fennel } & \multirow[t]{2}{*}{ Foeniculum vulgare } & Slovaki & & $14.57 \pm 0.70$ & nd & nd & 14.57 & nd & - \\
\hline & & Spain & & nd & nd & nd & - & $0.91 \pm 0.07$ & 0.91 \\
\hline \multirow[t]{2}{*}{ Cardamom } & \multirow[t]{2}{*}{ Elettaria cardamomиm } & Slovaki & & nd & $1.94 \pm 0.03$ & nd & 1.94 & nd & - \\
\hline & & Spain & & nd & nd & nd & - & nd & - \\
\hline \multirow[t]{2}{*}{ Clove } & \multirow[t]{2}{*}{ Syzygium aromaticum } & Slovaki & & $14.70 \pm 0.37$ & nd & nd & 14.70 & nd & - \\
\hline & & Spain & & nd & nd & nd & - & nd & - \\
\hline \multirow[t]{2}{*}{ Coriander } & \multirow[t]{2}{*}{ Coriandrum sativum } & Slovaki & & $4.73 \pm 0.38$ & $0.74 \pm 0.04$ & $0.59 \pm 0.01$ & 6.06 & nd & - \\
\hline & & Spain & & nd & nd & $0.53 \pm 0.04$ & 0.53 & $1.01 \pm 0.06$ & 1.01 \\
\hline \multirow[t]{2}{*}{ Nutmeg } & \multirow[t]{2}{*}{ Myristica fragrans } & Slovaki & & $1.30 \pm 0.04$ & nd & nd & 1.30 & nd & - \\
\hline & & Spain & & nd & nd & $0.20 \pm 0.02$ & 0.20 & nd & - \\
\hline Allspice & Pimenta dioica & Slovaki & & $1.13 \pm 0.01$ & nd & $0.23 \pm 0.00$ & 1.36 & nd & - \\
\hline & & Spain & & nd & nd & $0.37 \pm 0.03$ & 0.37 & nd & - \\
\hline Cinnamon & Cinnamomum burmanni & Slovaki & & nd & nd & $0.18 \pm 0.01$ & 0.18 & nd & - \\
\hline & & Spain & & nd & nd & $0.18 \pm 0.00$ & 0.18 & $0.24 \pm 0.01$ & 0.24 \\
\hline & & & II & nd & nd & $0.21 \pm 0.00$ & 0.21 & nd & - \\
\hline Vanilla & Vanilla planifolia & Slovaki & & $2.98 \pm 0.13$ & nd & nd & 2.98 & nd & - \\
\hline & & Spain & & nd & nd & nd & - & nd & - \\
\hline Ginger & Zingiber officinale & Slovak & & $2.63 \pm 0.06$ & nd & nd & 2.63 & nd & - \\
\hline & & Spain & & nd & nd & nd & - & nd & - \\
\hline Peppermint & Mentha piperita & & & nd & nd & $0.67 \pm 0.03$ & 0.67 & $0.92 \pm 0.02$ & 0.92 \\
\hline Parsley & Petroselinum crispum & & & nd & nd & $0.50 \pm 0.05$ & 0.50 & $0.60 \pm 0.02$ & 0.60 \\
\hline Thyme & Thymus vulgaris & & & nd & nd & $0.61 \pm 0.06$ & 0.61 & $0.83 \pm 0.08$ & 0.83 \\
\hline Laurel & Laurus nobilis & & & nd & nd & nd & - & $0.52 \pm 0.04$ & 0.52 \\
\hline Garlic & Allium sativum & & & nd & nd & $0.11 \pm 0.01$ & 0.11 & nd & - \\
\hline Cumin & Cuminum cyminum & & & nd & nd & nd & - & $0.34 \pm 0.01$ & 0.34 \\
\hline Black paper & Piper nigrum & & & nd & nd & nd & - & nd & - \\
\hline Hot pepper (mild) & Capsicum аппиит & & & nd & nd & $0.18 \pm 0.01$ & 0.18 & nd & - \\
\hline Hot pepper (hot) & & & & nd & nd & $0.16 \pm 0.01$ & 0.16 & nd & - \\
\hline Oregano & Origanum vulgare & Spain & I & nd & nd & $0.54 \pm 0.06$ & 0.54 & $0.98 \pm 0.10$ & 0.98 \\
\hline & & & II & nd & nd & $0.55 \pm 0.01$ & 0.55 & $0.83 \pm 0.01$ & 0.83 \\
\hline
\end{tabular}

$n d$ not detected, I, II types of spices

Table 3. In a group of selected perfluoroalkyl substances (7 perfluoroalkyl carboxylic acids and 3 perfluoroalkane sulfonates), three acids such as butanoic (PFBA), heptanoic (PFHpA) and octanoic (PFOA) and one sulfonate-perfluorobutane (PFBS) were quantified. Perfluorobutanoic acid was detected in 10 Slovak spice samples and ranged from $1.13 \mathrm{ng} \mathrm{g}^{-1}$ for allspice to $37.82 \mathrm{ng} \mathrm{g}^{-1}$ for star anise. Spanish spices was free from
PFBA contamination. The perfluorobutanoic acid concentration in Slovak spices increased in the following order: allspice $<$ nutmeg $<$ white pepper $<$ ginger $<$ vanilla $<$ coriander $<$ fennel $<$ clove $<$ anise $<$ star anise. Perfluoroheptanoic acid (PFHpA) was identified only in two samples of Slovak spices: cardamom $\left(1.94 \mathrm{ng} \mathrm{g}^{-1}\right)$ and coriander $\left(0.74 \mathrm{ng} \mathrm{g}^{-1}\right)$. Perfluorooctanoic acid was quantified in the largest number of spice samples (19) but at not too 


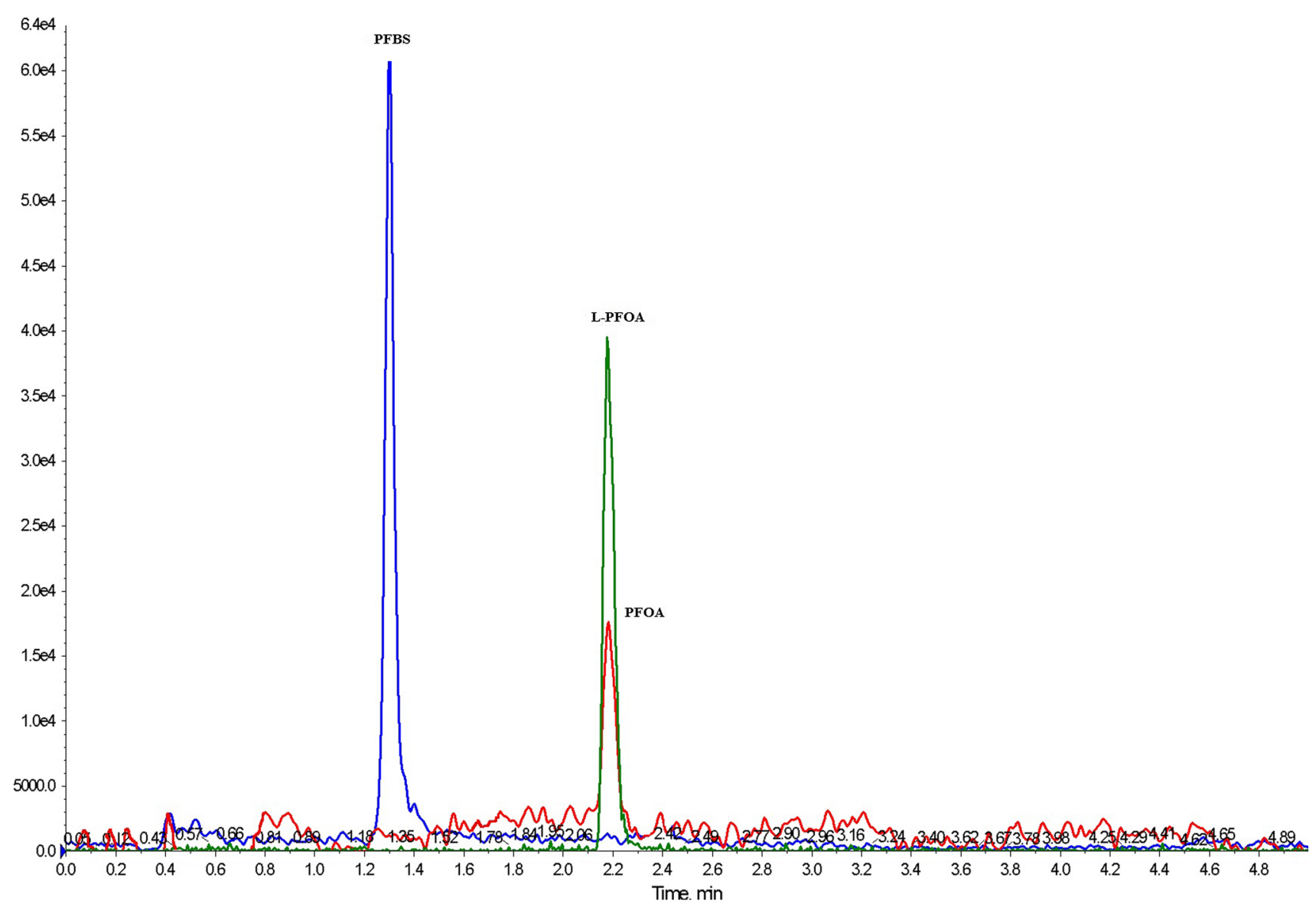

Fig. 3 LC-MS/MS chromatogram in MRM mode of selected PFASs in Spain coriander sample. Peaks description: PFBS perfluorobutane sulfonate, $P F O A$ perfluorooctanoic acid, L-PFOA $-{ }^{13} \mathrm{C}$ - perfluorooctanoic acid

high levels. There is ranged from $0.11 \mathrm{ng} \mathrm{g}^{-1}$ for garlic to $0.67 \mathrm{ng} \mathrm{g}^{-1}$ for peppermint. In both cases, it was spices from Spain. Generally, only four Slovak spices (anise, coriander, allspices and cinnamon) were contaminated by PFOA, while in Spanish spices PFOA was identified in 15 samples (additionally in star anise, nutmeg, peppermint, parsley, thyme, garlic, hot paper (mild and hot) and oregano). For both countries of origin, no increasing PFOA concentration trend has been noticed in investigated samples. In all cases, besides cinnamon, when analyzed samples were from two countries of origin globally, higher concentration of perfluoroalkyl carboxylic acids in Slovak spices was noticed. The highest amount of PFCAs was determined in Slovak star anise.

Reverse situation have placed in case of perfluoroalkane sulfonates. Perfluorobutane sulfonate is only one qualified in 12 Spanish spices and ranged from $0.24 \mathrm{ng} \mathrm{g}^{-1}$ for cinnamon to $1.01 \mathrm{ng} \mathrm{g}^{-1}$ for coriander. No PFASs were detected in Slovak spice samples. An example of LC-MS/ MS chromatogram of spice sample is shown in Fig. 3.

There were some inconveniences with data received in this study comparing with another author data because, to our knowledge, no other studies regarding PFASs concentration in spice samples have been reported in the available literature. Looking at the existing literature, even EFSA [46] provides no information about the content of perfluoroalkyl substances in spices and the results presented in this paper are of great value. Following the above-mentioned document, authors' foods of plant origin $(n=508)$ have been analyzed for a broad range of PFASs, but only a very limited number of positive results were found in the food of plant origin divided into grain and grain-based products, vegetables and vegetable products, potatoes and potatoes products, and legumes, nuts and oil seeds groups. Contamination levels ranged between 0.01 and $2 \mathrm{ng} \mathrm{g}^{-1}$ for the various PFASs detected. Spices were included in this division for a food groups to "Other foods" section with fruit juice, soft drinks, herbs, dressing, snacks and desserts. It is a much diversified group of food products, on the basis of which, it cannot be concluded about the spices contamination by perfluoroalkyl substances. Other scientific reports of EFSA [47] indicated that upper bond mean, calculated by weighting the results for the number of pooled samples for PFDA concentration, was $0.0095 \mu \mathrm{g} \mathrm{kg}^{-1}$. Only two 
undefined spice samples were analyzed from 30 samples taken considering the pooled samples. Proportion of leftcensored results calculated on the number of reported analyses (LB\%) was $100 \%$. To our best knowledge, no other information about perfluoroalkyl substances contamination level of spices is available.

A person can be exposed to these compounds through the consumption of food and drinking water, as a result of their migration to food from packaging as well as through the lungs and skin by daily contact with the products that surround us [48]. This is followed by the ingestion of dust and inhalation of air [49]. However, bioaccumulation in food products is the most significant source of human exposure to PFASs [50]. There are no systematic investigations of the occurrence of perfluoroalkyl substances in European food available that could form a basis for a comprehensive dietary exposure assessment. Due to the lack of data, it has not been possible to perform an assessment of the relative contribution from different foodstuffs to human exposure to PFASs. Based on the limited information available, seafood, in particular, is considered a major source of PFASs in humans [32], but contaminated drinking water can also be an important source of exposure in contaminated areas [49]. The average consumption of spices in Europe is approximately $0.5 \mathrm{~g} \mathrm{day}^{-1}$, while in Asia and northern Africa, it is many times higher [51]. Average content of PFASs in this evaluation has a value $4.67 \mathrm{ng} \mathrm{g}^{-1}$ giving $2.33 \mathrm{ng} \mathrm{day}^{-1}$ per person. As was mentioned before, there is no legislation for perfluoroalkyl substances in food or feed within the EU so it is impossible to compare these values with some limitation. In recent decades, there is a growing interest in vegetarian diets and the favorable impact of reducing the consumption of animal products on the health of the people. In the diet, where traditionally rarely or never used the meat are used in large quantities numerous spices [52]. The recipes of some dishes in Indian cuisine include up to 60 different spices. However, level of spices contamination is quite low and PFASs are well absorbed from the intestines and accumulated primarily in the liver [50]. Man particularly finds it difficult to expel the substance from the body. For example, the half-life of PFOA in the adult rat serum is 7.5 days, while the human is approx. 9 years. Therefore, although there is no clear threat contamination of PFASs, there is a need to be caution and monitor their level in food.

\section{Conclusion}

This study provided for the first time evidences for spices contamination by PFASs from the two European countries diametrically located. The dispersive solid phase extraction (d-SPE) and micro-HPLC-MS/MS detection were highly applicable for the determination of selected perfluoroalkyl carboxylic acids and perfluoroalkane sulfonates in spices. The use of the polymer-based sorbent-ENV for the efficient PFASs extraction from spices based on QuEChERS method can be recommended. The level of spices contamination by perfluoroalkyl substances indicates that commonly and daily used spices may be contributor to the overall contamination of food by PFASs.

Acknowledgments We gratefully acknowledge project Grant No. 2015/17/B/NZ9/01623 from the National Science Centre, Poland.

\section{Compliance with ethics requirements}

Conflict of interest Magdalena Surma declares that she has no conflict of interest. Mariusz Piskuła declares that he has no conflict of interest. Wiesław Wiczkowski declares that he has no conflict of interest. Henryk Zieliński declares that he has no conflict of interest.

Ethical standards Magdalena Surma declares that she has not received any honoraries from any commercial companies.

Human and animal rights This article does not contain any studies with human or animal subjects.

Open Access This article is distributed under the terms of the Creative Commons Attribution 4.0 International License (http://creativecommons.org/licenses/by/4.0/), which permits unrestricted use, distribution, and reproduction in any medium, provided you give appropriate credit to the original author(s) and the source, provide a link to the Creative Commons license, and indicate if changes were made.

\section{References}

1. Mueller M, Hobiger S, Jungbauer A (2010) Anti-inflammatory activity of extracts from fruits, herbs and spices. Food Chem 122:987-996

2. Tajkarimi MM, Ibrahim SA, Cliver DO (2010) Antimicrobial herb and spice compounds in food. Food Control 21:1199-1218

3. Viuda-Martos M, Ruiz-Navajas Y, Fernández-López J, PérezÁlvarez JA (2007) Antifungal activities of thyme, clove and oregano essential oils. J Food Saf 27:91-101

4. Kaefer CM, Milner JA (2008) The role of herbs and spices in cancer prevention. J Nutr Biochem 19:347-361

5. Park JB (2011) Identification and quantification of a major antioxidant and anti-inflammatory phenolic compound found in basil, lemon thyme, mint, oregano, rosemary, sage, and thyme. Int J Food Sci Nutr 62(6):577-584. doi:10.3109/09637486.2011. 562882

6. Suhaj M (2006) Spice antioxidants isolation and their antiradical activity: a review. J Food Compos Anal 19:531-537

7. Przygodzka M, Zielińska D, Ciesarová Z, Kukurová K, Zieliński $\mathrm{H}$ (2014) Comparison of methods for evaluation of the antioxidant capacity and phenolic compounds in common spices. LWT-Food Science and Technology 58:321-326

8. Carlsen MH, Halvorsen BL, Holte K, Bohn SK, Dragland S, Sampson L, Willey C, Senoo H, Umezono Y, Sanada C, Barikmo I, Berhe N, Willett WC, Phillips KM, Jacobs DR Jr, Blomhoff R (2010) The total antioxidant content of more than 3100 foods, 
beverages, spices, herbs and supplements used worldwide. Nutr J 9(3): $1-11$

9. Ozbey A, Uygun U (2006) Effect of drying on organophosphorus pesticide residues in peppermint (Mentha piperita L.). Bull Environ Contam Toxicol 77:638-642

10. Zhu YZ, Zhao MA, Feng YN, Kim JH (2014) Multiresidue method for the determination of 227 pesticides in hot pepper (Capsicum annuиm L.) by liquid chromatography with tandem mass spectrometry. J Sep Sci 37:2947-2954

11. Bielicka-Giełdoń A, Ryłko E, Bojanowska I (2011) Evaluation of metals content in herbs and spices available on the polish market. Ochrona Środowiska i Zasobów Naturalnych 48:492-497

12. Rebane R, Leito I, Yurchenko S, Herodes K (2010) A review of analytical techniques for determination of Sudan I-IV dyes in food matrixes Riin Rebane. J Chromatogr A 1217:2747-2757

13. Botek P, Poustka J, Hajšlová J (2007) Determination of banned dyes in spices by liquid chromatography-mass spectrometry. Czech J Food Sci 25(1):17-24

14. Ferrer Amate $\mathrm{C}$, Unterluggauer H, Fischer RJ, Fernández-Alba AR, Masselter S (2010) Development and validation of a LCMS/MS method for the simultaneous determination of aflatoxins, dyes and pesticides in spices. Anal Bioanal Chem 397:93-107

15. Pokrzywa P, Cieślik E, Topolska K (2007) The evaluation of mycotoxins content in selected food product. Food Sci Technol Qual 3(52):139-146

16. Yeung LWY, Taniyasu S, Kannan K, Xu DZY, Guruge KS, Lam PKS, Yamashita N (2009) An analytical method for the determination of perfluorinated compounds in whole blood using acetonitrile and solid phase extraction methods. J Chromatogr 1216:4950-4956

17. Gomis MI, Wang Z, Scheringer M, Cousins IT (2015) Selected physicochemical aspects of poly- and perfluoroalkylated substances relevant to performance, environment and sustainability_Part one. Chemosphere 129:4-19. doi:10.1016/j. chemosphere.2014.08.039

18. Mørck TA, Nielsen F, Nielsen JKS, Siersma VD, Grandjean P, Knudsen LE (2015) PFAS concentrations in plasma samples from Danish school children and their mothers. Chemosphere 129:203-209. doi:10.1016/j.chemosphere.2014.07.018

19. Toms LML, Thompson J, Rotander A, Hobson P, Calafat AM, Kato K, Ye X, Broomhall S, Harden F, Mueller JF (2014) Decline in perfluorooctane sulfonate and perfluorooctanoate serum concentrations in an Australian population from 2002 to 2011. Environ Int 71:74-80. doi:10.1016/j.envint.2014.05.019

20. Hansen KJ, Clemen LA, Ellefson ME, Johnson HO (2001) Compound-specific, quantitative characterization of organic fluorochemicals in biological matrices. Environ Sci Technol 35:766-770

21. Olsen GW, Mair DC, Reagen WK, Ellefson ME, Ehresman DJ, Butenhoff JL, Zobel LR (2007) Preliminary evidence of a decline in perfluorooctanesulfonate (PFOS) and perfluorooctanoate (PFOA) concentrations in American Red Cross blood donors. Chemosphere 68:105-111

22. Llorca M, Farré M, Picó Y, Barceló D (2009) Development and validation of a pressurized liquid extraction liquid chromatography-tandem mass spectrometry method for perfluorinated compounds determination in fish. J Chromatogr A 1216:7195-7204

23. Giesy JP, Kannan K (2001) Global Distribution of Perfluorooctane Sulfonate in Wildlife. Environ Sci Technol 35:1339-1342

24. EPA, 2010/2015 PFOA Stewardship Program-2014 Annual Progress Reports

25. EFSA, European Food Safety Authority (2008) Perfluorooctane sulfonate (PFOS), perfluorooctanoic acid (PFOA) and their salts. Scientific opinion of the panel on contaminants in the food chain. The EFSA J 653:1-131
26. Surma M, Zieliński H (2015) What do we know about the risk arising from perfluorinated. Pol J Environ Stud 24(2):449-457

27. Loganathan BG, Lam PKS (2012) Global contamination trends of persistent organic chemicals, Edition: First, Chapter: 26, Publisher: CRC Press, Taylor \& Francis Group, 593-628

28. Commission Recommendation (2010/161/EU) of 17 March 2010 on the monitoring of perfluoroalkylated substances in food

29. Guillarme D, Ruta J, Rudaz S, Veuthey JL (2010) New trends in fast and high-resolution liquid chromatography: a critical comparison of existing approaches. Anal Bioanal Chem 397:1069-1082

30. Ye X, Schoenfuss HL, Jahns ND, Delinsky AD, Strynar MJ, Varns J, Nakayama SF, Helfant L, Lindstrom AB (2008) Perfluorinated compounds in common carp (Cyprinus carpio) fillets from the Upper Mississippi River. Environ Int 34(7):932-938

31. Taniyasu S, Kannan K, So MK, Gulkowska A, Sinclair E, Okazawa T, Yamashita N (2005) Analysis of fluorotelomer alcohols, fluorotelomer acids, and short- and long-chain perfluorinated acids in water and biota. J Chromatogr A 1093:89-97

32. Haug LS, Salihovic S, Jogsten IE, Thomsen C, van Bavel B, Lindström G, Becher G (2010) Levels in food and beverages and daily intake of perfluorinated compounds in Norway. Chemosphere 80:1137-1143

33. Taniyasu S, Kannan K, Horii Y, Hanari N, Yamashita N (2003) A survey of perfluorooctane sulfonate and related perfluorinated organic compounds in water, fish, birds, and humans from Japan. Environ Sci Technol 37:2634-2639. doi:10.1021/es0303440

34. Guruge KS, Manage PM, Yamanaka N, Miyazaki S, Taniyasu S, Yamashita N (2008) Species-specific concentrations of perfluoroalkyl contaminants in farm and pet animals in Japan. Chemosphere 73:210-215. doi:10.1016/j.chemosphere.2006.12.105

35. Yamashita N, Kannan K, Taniyasu S, Horii Y, Okazawa T, Petrick G, Gamo T (2004) Analysis of perfluorinated acids at parts-per-quadrillion levels in seawater using liquid chromatography-tandem mass spectrometry. Environ Sci Technol 38:55225528. doi:10.1021/es0492541

36. So MK, Tanyasu S, Lam PKS, Zheng GJ, Giesy JP, Yamashita N (2006) Alkaline digestion and solid phase extraction method for perfluorinated compounds in mussels and oysters from south China and Japan. Arch Environ Contam Toxicol 50:240-248. doi:10.1007/s00244-005-7058-x

37. Lacina O, Hradkowa P, Pulkrabova J, Hajslova J (2011) Simple, high throughput ultra-high performance liquid chromatography/tandem mass spectrometry trace analysis of perfluorinated alkylated substances in food of animal origin: milk and fish. J Chromatogr A 1218:4312-4321. doi:10.1016/j. chroma.2011.04.061

38. Anastassiades M, Lehotay SJ, Stajnbaher D, Schenck FJ (2003) Fast and easy multiresidue method employing acetonitrile extraction/partitioning and "dispersive solid-phase extraction" for the determination of pesticide residues in produce. J AOAC Int 86(2):412-431

39. Surma M, Wiczkowski W, Cieślik E, Zieliński H (2015) Method development for the determination of PFOA and PFOS in honey based on the dispersive solid phase extraction (d-SPE) with micro-UHPLC-MS/MS system. Microchem J 121:150-156

40. Surma M, Giżejewski Z, Zieliński H (2015) Determination of perfluorinated sulfonate and perfluorinated acids in tissues of free-living European beaver (castor fiber L.) by d-SPE/microUHPLC-MS/MS. Ecotoxicol Environ Saf 120:436-444

41. Cieślik E, Sadowiska-Rociek A, Molina Ruiz JM, Surma-Zadora M (2011) Evaluation of QuEChERS method for the determination of organochlorine pesticide residues in selected groups of fruits. Food Chem 125:773-778

42. Sadowska-Rociek A, Surma M, Cieślik E (2013) Application of QuEChERS method for simultaneous determination of 
pesticide residues and PAHs in fresh herbs. B Environ Contam Tox 90:508-513

43. Surma M, Sadowska-Rociek A, Cieślik E (2014) The application of d-SPE in the QuEChERS method for the determination of PAHs in food of animal origin with GC-MS detection. Europ Food Res Technol 238:1029-1036

44. Sadowska-Rociek A, Surma M, Cieślik E (2015) Determination of polycyclic aromatic hydrocarbons in coffee and coffee substitutes using dispersive SPE and gas chromatography-mass spectrometry. Food Anal Methods 8(1):109-121

45. Ferrer C, Lozano A, Agüera A, Girón J, Fernández-Alba AR (2011) Overcomin matrix effects using the dilution approach in multiresidue methods for fruits and vegetables. J Chrmoatogr A 1218:7634-7639

46. EFSA, European Food Safety Authority (2011) Results of the monitoring of perfluoroalkylated substances in food in the period 2000-2009. The EFSA J 9:2016-2049

47. EFSA, European Food Safety Authority (2012) Perfluoroalkylated substances in food: occurrence and dietary exposure. The EFSA J 10(6):2743
48. Jogsten IE, Perello G, Llebaria X, Bigas E, Marti-Cid R, Karrman A, Domingo JL (2009) Exposure to perfluorinated compounds in Catalonia, Spain, through consumption of various raw and cooked foodstuffs, including packaged food. Food Chem Toxicol 47:1577-1583

49. Fromme H, Schlummer M, Möller A, Gruber L, Wolz G, Ungewiss J, Böhmer S, Dekant W, Mayer R, Liebl B, Twardella D (2007) Exposure of an adult population to perfluorinated substances using duplicate diet portions and biomonitoring data. Environ Sci Technol 41: 7928-7933

50. Tittlemer SA, Pepper K, Seymour C, Moisey J, Bronson R, Cao XL, Dabeka RW (2007) Dietary exposure of Canadians to perfluorinated carboxylates and perfluorooctane sulfonate via consumption of meat, fish, fast foods, and food items prepared in their packaging. J Agric Food Chem 55:3203-3210

51. Hozyasz K, Chełchowska M (2005) Efekty wprowadzenia przypraw orientalnych do polskiej diety effects of the introduction of oriental species to polish diet. Postępy Fitoterapii 3-4:68-70

52. Lampe JW (2003) Spicing up a vegetarian diet: chemopreventive effects of phytochemicals. Am J Clin Nutr 78:579-583 